\title{
The Market Effect of Cultural Transmission in Chinese Costume Dramas: A Case Study of the Untamed
}

\author{
Guo Lanying, Jiang Jianxia* \\ China Jiliang University Humanities and Foreign Languages College, Hangzhou, Zhejiang, China \\ gly@cjlu.edu.cn, 360386681@qq.com \\ Jiang jianxia*
}

\section{Keywords: The Untamed, Cultural Transmission, Costume Dramas, Market}

\begin{abstract}
In recent years, the film and television cultural industry has developed rapidly. Since China no longer stays in the single way of importing American dramas, Korean dramas, and Thai dramas, a large number of costume dramas have been exported overseas, and costume dramas have embodied the industrialization of Chinese cultural transmission. A good costume drama presents the beauty of national style and shows the unique charm of Chinese culture. It is a brochure of Chinese traditional culture and brings the broad market to China. This article takes The Untamed as an example which is popular both in China and Thailand for analysis. From the aspects of fashion design, props and the pursuit of Thai netizens, it proves the market effect of Cultural Transmission in Chinese costume dramas.
\end{abstract}

\section{Introduction}

"In the era of globalization, the economy and culture are highly integrated and inseparable" (Sheng Ru\&Ziru Wang, 2019). With the development of the film and television industry, the industrialization of film and television culture has become an indispensable part in the process of cultural transmission. For example, American dramas, Korean dramas and Thai drama all had been popular in China. China's costume dramas had been widely spreading since the late 1980s. Now China's costume drama has become more mature, with arisen sales prices but without the diminishment of popularity. The film and television industry as the core industry of the cultural industry, high concentration of creativity is necessary. At present, The Untamed is standing out as the most popular costume drama in China spreading to Thailand, South Korea, Japan, North America, South America and Europe soon in its development of markets. "Capital is a 'double-edged sword' to promote the prosperity of the film industry" (Zhang Sanxi, 2018). "Cultural industry should not be the accessory of Capital Economics" (Gao Shangxue\&Li Xin, 2019). We should lay emphasis on cultural transmission rather than Capital Economics. In fact, it is the Chinese culture that succeeds The Untamed.

\section{Fashion design in Chinese culture}

The costumes of this drama mainly use Hanfu. Hanfu is the main costume of ancient China, and it is inseparable from Chinese etiquette. The costume conveys many characteristics of social such as the age, nationality, and status of the characters. Following the trend of costume dramas, people's acceptance of Hanfu has become higher and higher. The drama uses a variety of methods to promote its Hanfu culture. At the very beginning, the actors in the drama are dressed in Hanfu as models for public attraction. Still, Hanfu styles are diverse, and each set of Hanfu is tailor-made for the characters. In addition, to meet the needs of everyone who wants to buy the same Chinese costume in the drama, The Untamed has opened its own shop on Taobao, named The Untamed official mall. The store has a total of 426,000 fans, and now has 12 Chinese costumes, covering eight characters in the play. Now they open a new store, named The Untamed Flagship Store. With the rise of the Hanfu cultural industry, Hanfu's buyers are no longer confined to the Chinese and 
some foreign friends can hardly conceal their love for Hanfu. For example, after The Untamed aired, the Thai netizens who wear the same Hanfu as actor shared the photos on their own dating software, which was well received by netizens. Although there are differences in clothing and aesthetics between different countries, more and more foreigners have accepted Hanfu as the symbol of Chinese Han culture. As we all known, Hanfu cultural industry will own more market and broaden prospect of development. In addition, with the popularity of the play, the forehead belt once again appeared in front of people. Affected by the characters in the play, many people want to follow the characters in the play and put on the forehead belt. Therefore, the similar forehead belts can be sold in The Untamed Flagship Store and The Untamed official mall.

Fashion design plays an important role in the costume drama. Each costume drama takes much time to design clothes in the early stage. The result in fashion design is undoubtedly the biggest contributor, and the marketization from Hanfu to forehead decoration brought by the costumes is going to bring a huge market.

\section{Chinese traditional instruments}

Chinese traditional instruments are essential in Chinese history. Due to the introduction of Western instruments and some shortcomings of traditional instruments, people began to learn Western instruments and gradually forgot Chinese traditional instruments. The protagonist in the TV play The Untamed uses traditional Chinese instruments as weapons to show the unique charm of traditional Chinese instruments.

One protagonist Wei wuxian uses the flute as his portable instrument and the winning weapon. The flute has long history and the sound quality of it in China is basically stable during the Song Dynasty to the Qing Dynasty. In the Song and Qing Dynasties, flutes had appeared in folk music and folk art and became an indispensable instrument in the folk music. In the play, Wei Wuxian's flute has the name of "ghost flute", which can control 10,000 corpses and no one can compete with it. In Chinese history, flute has no such usage, but the play gives the flute a mysterious color in this way. The Untamed not only remind us the existence of it, but also transmit it to other country.

Another protagonist Lan Wangji is bound by three thousand rules, dignified and elegant. The instrument is the Guqin that matches his temperament. In fact, the lyre used by him, also known as Guqin, has been listed by UNESCO as the second list of the world's representative works of human intangible cultural heritage. On May 20, 2006, Guqin Art was approved by the State Council to be included in the first batch of national intangible cultural heritage. Guqin was mainly passed down through oral communication, and then there was a Guqin text. The Guqin skills of Lan's family are also recorded and disseminated through the form of Guqin text. The Guqin is a symbol of the gentleman and the ancient literati must learn Guqin.Lan's family are the best one who can match to gentleman among the five major families, so they use Guqin as a unique skill. When we are playing the Guqin, the player is required to calm down and use the Guqin to express his inner heart. Therefore, The literati pays attention to the cultivation of the heart and the Guqin becomes the first choice of the literati. Compared with ancient times, the art of Guqin has been declining day by day, and the popularity of Guqin is far less than it used to be. Through the drama The Untamed, Guqin reappeared in everyone's field of vision and told the Thai people about Chinese Guqin art.

Most of the songs in this drama combine traditional Chinese instruments, and 12 songs are included in the "The Untamed National Style Music Album". At present, there are 1,084,683 sales in QQ music alone, and 433,663 albums have been sold in KuGou. Each album is priced at 20 yuan and has been certified by three diamonds. In fact, KuGou also uses some sales strategies, such as supporting 5 albums so as to unlock long-length tidbits and classic monologues. Due to the popularity of TV series and actors, fans are willing to buy albums and disseminate albums spontaneously. 


\section{The industrialization process of The Untamed}

The prototype of The Untamed is the network novel "Mo Dao Zu Shi", so a large amount of book fans has been harvested before the TV series was broadcast. In addition, the novel also has related radio dramas and cartoons, and the evaluations are good. In the opening of The Untamed, it did not do much publicity before the broadcast and the broadcast platform only had Tencent video. Compared with other art forms, TV is now more competitive with commercial society. After the broadcast, the plot fits with the novel, and the selections of actors are appropriate. It restores the characters in the reader's mind. The costumes and props contain the beauty of the ancient style. The spirit of the characters conveys Confucianism and triggers people's resonance. From the perspective of accepting aesthetics, the core of accepting aesthetics is to start from the audience. In this era of fast-paced consumption centered on the audience, TV dramas can satisfy the expectations of the audience and be recognized by the public. It is precisely because the The Untamed was centered on the audience and took the psychology of the audience into account. If the The Untamed changes a large number of plots regardless of the audience psychology and the novel is changed beyond recognition, this drama won't be so prevalent.

Since the The Untamed had been broadcast, the amount of plays had increased day by day, and the score of Douban has been continuously improved. At present, there are 6.34 billion broadcasts, and the score in Tencent video is as high as 9.2. In the same time, The Untamed also strives to broaden its industry. First of all, the traditional songs in the TV series are included in the The Untamed National Style Music Album. It has a certain sales in the KuGou and QQ music platform. It not only spread the traditional Chinese instruments, but also promoted the Chinese traditional music. In addition, the The Untamed crew will also hold a concert in Nanjing on November 1. Except for this, we are easy to see reaction video from people all around the world in Bilibili platform. The content of the reaction video is that some foreigners or Chinese watch the MV of the songs in the albums and express their opinions. Some viewers who did not know this drama before said that they can't wait to see this drama after watching the MV of the songs. Secondly, They open a flagship store in Taobao and sell the clothing, props and other peripheral products in the drama so as to provide the authentic peripheral products for audiences. Thirdly, The Untamed is not limited to the Chinese market. It quickly spread throughout Thailand and The Untamed crew seized this opportunity and organized a meeting on September 21, 2019. In addition, The Untamed will play in South Korea after October 21. Even though Japan has not decided on time, but it has been confirmed that will be broadcast in Japan next year. Recently, The Untamed puts on the Netflix, and it is expected to be launched in North America, South America and Europe from October 25. Now the market for The Untamed is no longer limited to China and Thailand, but to the world.

\section{Conclusion}

In my opinion, The Untamed 's popularity is not an accident but a necessity. First of all, The Untamed as a TV drama adapted from a network novel, the fine production is the foundation for the excellent reputation in the later period. From the perspective of accepting aesthetics, taking full account of the psychology of the book fans, whether it is the costumes of the characters or the creation of the scene, all of them are carefully considered to fit the original novel. As a costume drama, The Untamed spreads Chinese traditional culture such as Hanfu culture and decoration through accessories and props. Then The Untamed not only produces TV dramas, but also develops surrounding industries. Firstly, The Untamed makes an album of Chinese traditional music in order to show the unique charm of Chinese traditional instruments and spread Chinese traditional music. Secondly, using Taobao as a platform to meet the needs of fans by selling peripheral products and expanding their influence. Last but not least, The Untamed has the ability to go abroad and broaden its market. As the People's Daily Online said, The Untamed writes the beauty of national style and uses Chinese elements to convey cultural confidence. "General Secretary Xi Jinping clearly stated at the celebration of the 95th anniversary of the founding of the Communist Party of China that the 
Chinese communists must adhere to the 'four self-confidences', such as social self-confidence, theoretical self-confidence, institutional self-confidence and cultural self-confidence. He also stressed that cultural self-confidence is a more basic, broader and deeper self-confidence" (Xi Jinping, 2016). Nowadays people began to pursue the spread of Chinese culture overseas through Chinese costume dramas, winning the imitation and admiration of other countries. In the end, it create a huge market for Chinese dramas.

All in all, the dissemination of culture based on the film and television cultural industry, the spread of culture between countries is inseparable from the network. We need to firmly catch this opportunity to create high-quality Chinese costume dramas and spread Chinese culture to various countries in order to broaden the scope of Chinese film and television cultural industry.

\section{Reference}

[1]Chenjia Li. Analysis on the Path of Intercultural Communication Ability Construction of Chinese Film and TV Drama. Journal of Jinan University (Social Science Edition),2011(1):11-18

[2] Gao Shangxue, Li Xin.The Wandering Earth Open up a New Chapter of Industrial Chain in Chinese Science Fiction Movies.Movie Review[J], pp. 41-44, 2019.

[3]Jianghong Han. On the Visual Communication of Costume art in Film Works[J].Chinese Collective Economy, 2011(12).

[4] Ru Sheng, Ziru Wang. The Status and Role of the Film and TV Industry in the National Cultural Industry Strategy. Youth Journalist, pp. 69-70, 2019.

[5]Zhang Sanxi, Yan Ling. Discuss on "Alienation" of Capital in the Film Industry. Journal of Beijing Union University: Humanities and Social Science Edition, pp. 81-82, 2018. 